\title{
O desenvolvimento da indústria bélica no Brasil e seu processo de Spin-Off
}

\author{
The development of the military industry in \\ Brazil and its Spin-off process
}

JOSÉ WLADIMIR FREITAS DA FONSECA*

\begin{abstract}
RESUMO: O objetivo deste artigo é analisar a cisão na indústria militar brasileira. Dois pontos importantes podem ser observados na literatura existente: primeiro, a verificação de que a cisão não ocorreu no caso brasileiro; e segundo, o número limitado de estudos de caso sobre esse assunto. Este artigo, que se baseia em grande parte no trabalho anterior do autor, argumenta que houve transferência de tecnologia da indústria militar brasileira para a indústria automobilística. Considerando o desenvolvimento da indústria militar brasileira, é possível identificar quatro fatores responsáveis pela promoção do spin-off: a origem da tecnologia; a maneira pela qual o desenvolvimento dessa tecnologia ocorre; a relação entre os setores militar e civil envolvidos na transferência de tecnologia; e finalmente a mobilização industrial.
\end{abstract}

PALAVRAS-CHAVE: Indústria bélica; inovação; efeito spin-off; P\&D.

ABSTRACT: The objective of this article is to analyze the spin-off in the Brazilian military industry. Two important points can be observed in the existing literature: first, the verification that the spin-off has not occurred in the Brazilian case; and second, the limited number of case studies on this subject. This article, which is based to a large extent on the author previous work, argues that there has been technology transference from the Brazilian military industry to the car industry. By taking into consideration the development of the Brazilian military industry, it is possible to identify four factors which are responsible for the promotion of the spin-off: the origin of technology; the way in which the development of this technology occurs; the relationship between the military and civil sectors involved in the transference of technology; and finally the industrial mobilization.

KEYWORDS: Military industry; innovation; spin-off effect; R\&D.

JEL Classification: O31; O32; L60.

\footnotetext{
* Professor da Universidade Federal do Paraná - UFPR, Curitiba/PR, Brasil. E-mail: wladi@sociais.ufpr.br.
} 
Os estudos sobre a indústria bélica brasileira começaram no meio acadêmico no final da década de setenta. Destacaram-se como precursores destes estudos, inicialmente, Clovis Brigagão e Renato Peixoto Dagnino, para mais tarde surgirem os trabalhos de José Drumond Saraiva, Ken Conca e Patrice Franco-Jones, entre outros. Duas grandes linhas serviram como eixos condutores dos trabalhos realizados sobre a indústria bélica brasileira neste período: a visão de sua dimensão econômica e a tentativa de identificar se o desenvolvimento tecnológico deste setor era ou não repassado com vantagem para a indústria civil nacional através do spin-off.

Com respeito ao segundo eixo condutor, Conca conclui, entre outras afirmativas e tornando-se um consenso, que inexiste uma medida objetiva ou estudos de casos adequados que tratem do spin-off brasileiro, e mais ainda, que " ... os casos disponíveis não são de repasse tecnológico para uso geral mas sim para usos específicos de alta tecnologia" (Conca, 1990, p. 141).

Dessa forma, este estudo procura analisar o spin-off na indústria bélica brasileira, dado que a maioria dos trabalhos realizados até o momento deram pouca ênfase a esta questão.

$\mathrm{O}$ artigo baseia-se em grande parte no trabalho anterior do autor, que identificou a existência do spin-off no Brasil a partir dos anos sessenta: Fonseca (1997), bem como nas contribuições de Conca (1990), Proença Junior (1987), Longo (1977), Rodrigues (1991) e Catharino (1980), além das pesquisas realizadas no IPD (Instituto de Pesquisa e Desenvolvimento do Exército), CTEx (Centro Tecnológico do Exército), IME (Instituto Militar de Engenharia do Exército) e Eceme (Escola de Comando e Estado-Maior do Exército). Na primeira seção faz-se uma análise das características gerais do spin-off da indústria bélica. Na seção 2 determinam-se e analisam-se as condicionantes do spin-off brasileiro e, finalizando, a seção 3 sumaria as principais conclusões.

\section{CARACTERÍSTICAS GERAIS DO SPIN-OFF DA INDÚSTRIA BÉLICA}

O spin-off é definido como um processo de disseminação tecnológica que tanto pode ocorrer na indústria civil como na indústria bélica. Isto ocorre por ser um fenômeno industrial tecnológico, o que não impede que ele se manifeste em todos os setores que se utilizam de tecnologia. No caso da indústria bélica, ele é uma consequência do uso intensivo da P\&D militar, que acaba gerando aplicações na· indústria civil devido à proximidade da tecnologia bélica a alguns setores importantes da economia.

A incidência maior ou menor do spin-off, ou até a sua não-existência, dependerá de algumas condicionantes que variam de intensidade de país para país. Mais ainda, é possível determinar que o spin-off não é uma condição que necessariamente deva ocorrer, como diversos estudos apontaram (Fonseca, 1997).

Foi proposta nos anos oitenta uma lógica geral a respeito do spin-off, que pode ser resumida em cinco pontos importantes, quais sejam:

1. Os militares demandariam eficácia de seus equipamentos a qualquer custo, 
somente possíveis por esforços específicos de P\&D em áreas de ponta. No caso dos Estados Unidos, isso ocorreria principalmente dentro das divisões de produtos militares de megacorporações.

2. Novas tecnologias são geradas dentro das divisões de produtos militares, onde os conhecimentos adquiridos permanecem dentro das corporações e acabam sendo absorvidos pelas linhas de produtos civis.

3. Uma vez inseridas na lógica empresarial do mercado, estas tecnologias modificam-se e passam a ter que atender aos requisitos de custo e desempenho civil, redefinindo novas pontas tecnológicas.

4. Os novos projetos militares tomam este novo patamar como base e uma vez mais ambicionam ultrapassá-lo, em função de suas necessidades específicas.

5. O ciclo recomeça.

Desta forma, a P\&D militar, nascida da produção bélica, promoveria o progresso tecnológico geral através da disseminação tecnológica. No entanto, alguns estudos iam mais longe e diziam que o spin-off era mais do que conveniente, era necessário, e que sem uma indústria militar não haveria progresso técnico (Proença Junior, 1987, p. 25).

Nestas constatações, três pontos merecem ser discutidos. Em primeiro lugar, pode-se constatar que existe (no mínimo, existiu) spin-off no Brasil, na medida em que os trabalhos desenvolvidos sobre o tema procuraram investigar, através do modelo dos EUA, uma regra geral para se aplicar ao caso brasileiro. Partindo-se da constatação da dependência tecnológica no setor bélico, o spin-off não ocorreria. Ao contrário, esta tecnologia não poderia concorrer com a tecnologia das empresas transnacionais aqui instaladas ou com as comercializadas em âmbito internacional. Nesse sentido, argumenta o professor Dagnino:

“... Um outro ponto importante refere-se às pretensas vantagens tecnológicas da produção de armamento para o país. Mesmo que se possa aceitar o argumento do spin-off, cuja existência tem sido crescentemente contestada nos países industrializados, é forçoso reconhecer que o mesmo dificilmente poderia ocorrer em países tecnologicamente dependentes como o Brasil. A regra geral vigente nos setores industriais civis é a utilização de tecnologia importada, uma vez que esta é mais barata, confiável, eficiente e prestigiada do que aquela que poderia ser localmente desenvolvida...” (Dagnino, 1993, p. 272).

Mesmo considerando a dependência tecnológica do Brasil, o spin-off ocorreu - e ocorre - no setor industrial, em parte em função do desenvolvimento da indústria bélica, e de outra, em função da capacitação industrial aperfeiçoada nas unidades militares e mais tarde na indústria civil bélica.

A sugestão de que o spin-off ocorreria apenas em megacorporações pode ser negada, uma vez que, no caso dos blindados brasileiros, as transferências de tecno- 
logia verificadas ocorreram em empresas de médio porte que conseguiram se alinhar com grandes firmas, tais como Ford, General Motors e Volkswagen ${ }^{1}$.

No entanto, é importante notar que enquanto nos EUA existe uma norma ${ }^{2}$ técnica que regulamenta e estimula a transferência de tecnologia bélica para a indústria civil doméstica, no Brasil a questão da transferência de tecnologia intersetores pode ser considerada mais recente e não foi objeto de um tratamento adequado, pelo menos até o final da década de oitenta.

O segundo ponto refere-se aos casos em que não se verificou precisamente o spin-off, mas algo muito parecido: a tecnologia dual. Neste caso, o mesmo produto que atendia a necessidades militares pode ser empregado sem adaptações à indústria civil, independente de o domínio da tecnologia ser nacional ou não.

Sendo um tipo de spin-off que não necessariamente é obrigado a passar pela terceira fase da lógica geral, a tecnologia dual pode ser definida também como uma manifestação tecnológica cujo emprego pode se dar diretamente no campo civil a partir de um desenvolvimento no setor bélico, sem haver, contudo, aqueles aprimoramentos, melhorias ou modificações. ${ }^{3}$ Um caso característico, ocorrido na década de setenta na indústria metalúrgica brasileira, foi o desenvolvimento dos aços especiais SAR 80 e SAR 120 (Aço Soldável de Alta Resistência). ${ }^{4}$ A história do surgimento deste aço está ligada à Bernardini e à Usiminas e ao desenvolvimento de três tipos de munições específicas.

Ao observar o desenvolvimento das munições do tipo Flecha, Perfurante e Carga Oca (que são capazes de perfurar a blindagem dos carros de combate), a Bernardini começou a desenvolver diversos estudos para que as chapas de aço que revestiam os carros de combate repotencializados limitassem a ação dos projéteis. Em estudo conjunto com a Usiminas, esta acabou desenvolvendo um tipo de aço da família SAR que impedia a ação daqueles projéteis (Assaoka, 1983). Foi feita então uma pequena encomenda deste tipo de aço especial para realizar os protótipos de carros de combate para teste. Mais tarde, o Ministério do Exército começou a demandar carros de combate com esta especificação - e que foi utilizada em larga escala por outra empresa do complexo bélico, a Engesa. Logo depois, o mesmo aço passou a ser aplicado em diversos produtos da indústria não-bélica.

É possível afirmar que houve uma transferência de tecnologia, mesmo que o produto não tenha precisado de outras adaptações para ser utilizado na indústria

\footnotetext{
${ }^{1} \mathrm{Na}$ pesquisa do autor, foi realizado um estudo de caso onde foi possível identificar a existência de spinoff na indústria automotiva.

${ }^{2}$ Estas normas são parte integrante da "Research, Development and Acquisition - Military-Civilian Technology Transfer"; Headquarters Department of the Army, Washington, D.C., 25 July 91.

${ }^{3}$ Num estudo do autor verifica-se um exemplo detalhado da tecnologia dual. Trata-se do Diferencial Controlado para Carros de Lagarta com Pivotamento, desenvolvido pela empresa ali estudada (Fonseca, 1997).

4 'Entrevista com o dr. José Roberto Nunes e o dr. Marcus A. S. França, ambos coronéis engenheiros da área de mecânica e metalurgia, cujos trabalhos realizados durante muito tempo, e até hoje, estão ligados à indústria bélica brasileira.
} 
civil, ferindo, dessa forma, a lógica geral. Por outro lado, o mesmo estudo da família do SAR levou a outras aplicações civis com modificações, que seguramente se encaixam na terceira etapa da lógica geral apontada acima.

Existe uma outra categoria de spin-off: aquela em que o produto final bélico, antes de ter sua tecnologia repassada para a indústria civil, aproveita insumos desenvolvidos com tecnologia estrangeira. Um exemplo mais recente no Brasil é o "Simulador de Míssil Superfície-Superfície", que o dr. Murilo Santos, do IPD do Exército Brasileiro, desenvolveu recentemente com sua equipe e que está na fase de testes. ${ }^{5}$ Tal simulador surgiu a partir de requisitos operacionais técnicos. Nesse projeto, a tecnologia final utilizada é inteiramente nacional. Segundo o dr. Murilo, o simulador utiliza alguns insumos de procedência da Europa, sobretudo a parte de hardware. Por outro lado, o software é inteiramente desenvolvido no Brasil, no próprio IPD do Exército Brasileiro. Sua função básica é simular o disparo da arma anticarro, a trajetória do míssil, sem a necessidade de utilizar alvos reais na forma de sucatas ou outros. As aplicações no campo civil estão na simulação de vôos de helicópteros, foguetes para lançamento de satélites, ensaios de deslocamento e velocidade de metrôs, entre outras.

O terceiro ponto refere-se à forma como ocorreu o spin-off nos EUA e no Brasil. Enquanto a lógica geral se aplica ao caso norte-americano, devido a todo um aparato institucional, tal como normas e legislações, no Brasil o spin-off repousa em outras condicionantes.

\section{AS CONDICIONANTES DO SPIN-OFF BRASILEIRO}

É possível determinar quatro condicionantes responsáveis pela promoção do spin-off: a origem da tecnologia bélica, a forma como ocorre o desenvolvimento desta tecnologia, a relação entre os dois setores envolvidos na dinâmica e a mobilização industrial.

\section{A origem da tecnologia bélica}

Por origem da tecnologia entende-se a procedência desta, desenvolvida para fins bélicos. $\mathrm{Na}$ verdade, é saber se o produto originado no país é resultado direto e exclusivo da capacitação técnica de "cérebros" brasileiros, ou se há a capacitação técnica mas não há produtos realizados, daí a necessidade de buscar fora do setor doméstico insumos e/ou cérebros.

Embora o Brasil, desde o século XVIII, fabricasse armas e munições, o spin off era limitado pela pouca incidência de tecnologia no fabrico destes produtos. A

\footnotetext{
${ }^{5}$ Entrevista realizada com o dr. Murilo Cesar Gonçalves dos Santos, cel. engenheiro da área de mecânica e metalurgia; IPD do Exército.
} 
incidência maior do spin-off somente ocorreria após a instalação no país de uma indústria siderúrgica, o que nos leva a meados da década de quarenta.

Por outro lado, o desenvolvimento da capacitação técnica militar e o uso intensivo da P\&D tiveram seu início no Brasil - em grande escala - a partir da compra de tecnologia bélica originária da Europa e dos EUA, o que limitou o spinoff no país.

A tecnologia bélica tem um preço elevado no mercado, devido às características monopolísticas do mesmo. Nele, o proprietário da tecnologia é protegido por um monopólio legal, através do sistema de patentes.

Ainda mais, o comércio de tecnologia tem uma particularidade que é a assimetria que normalmente se verifica quanto aos participantes no processo, principalmente quando o vendedor pertence a um país desenvolvido e o comprador, não. $\mathrm{O}$ exportador, neste caso, é invariavelmente um especialista que possui experiência em excelentes condições de informação. O comprador, por sua vez, é geralmente uma empresa ou instituição relativamente modesta, que não dispõe daquelas condições verificadas ou, invariavelmente, não detém o savoir faíre (Longo, 1977, p. 34).

Além destes fatores, o custo marginal da tecnologia para o fornecedor é baixíssimo, haja vista sua utilização e amortização no mercado interno, ao passo que para o comprador este custo eleva-se consideravelmente caso opte por produzi-la em vez de importá-la. Diante disto, o comprador fica com uma baixa capacidade de negociação, resultando na compra a altos preços e na aceitação de inúmeras restrições feitas pelo fornecedor.

Uma questão relevante é que, de certa forma, o mercado de armas é diferente do de qualquer outro produto. Quando se faz uma nova arma o objetivo não é comercial, mas, ao contrário, é o segredo. Circunstâncias diversas (por exemplo, sua superação por outro concorrente e/ou motivos políticos) podem fazer com que o produto seja vendido, mas não é esse necessariamente o objetivo.

Desta forma, entende-se que existem dois níveis de indústria bélica: um de tecnologia mais ou menos difundida, que funciona como qualquer outro mercado ("gostaríamos que a polícia do país X comprasse as pistolas que fabricamos"); o outro, com produtos que envolvem segredos, e cujo acesso deve ser limitado para os inimigos. Por isso, a baixa capacidade de negociação deixa de ser um fenômeno exclusivo do mercado e passa também a ocorrer em função do segredo tecnológico que é essencial ao mercado de armamento.

Normalmente, quando são divulgadas compras de tecnologia do setor bélico no exterior e apontadas suas vantagens, são omitidas as cláusulas restritivas, pois estas são altamente prejudiciais à própria empresa nacional e ao setor industrial como um todo. As três mais importantes são: 1) proibição ou limitação de exportações e vendas dos produtos elaborados para determinados países; 2) obrigatoriedade de informar ao cedente sobre qualquer melhoria introduzida na tecnologia comprada; 3 ) obrigatoriedade de utilização de matéria-prima, bens intermediários, máquinas e equipamentos fornecidos pelo vendedor (Longo, 1977, p. 35; Mendes, 1979, p. 15).

Com respeito ao primeiro item observa-se que ele limita a incidência do spin- 
off pelo menos sob dois aspectos: restringe sua produção ao tamanho do mercado interno e, consequentemente, limita seu poder de encadeamento. Mesmo durante o boom da indústria bélica brasileira - no final dos anos setenta e início dos oitenta o mercado doméstico da indústria bélica brasileira era restrito por conta da situação em que se encontrava o país, principalmente o setor público. As dívidas interna e externa brasileiras foram as grandes responsáveis pelas restrições impostas aos gastos do governo com a demanda doméstica de armas, fazendo com que ela fosse restringida pela Marinha, Exército e Aeronáutica. Mas, em se tratando do início da formação bélica pesada do Brasil, ou seja, meados dos anos sessenta, esta demanda era ainda muito menor, vis à vis o acordo de abastecimento de armas que o Brasil mantinha com os EUA, e com alguns países da Europa.

Com uma demanda doméstica restrita e com a dificuldade de tentar buscar mercados externos, a disseminação do spin-off teve que esperar a formação de um tecido industrial bélico no qual as empresas civis, através de um efeito multiplicador de investimentos, lançassem bases para essa disseminação.

Em realidade, a formação do tecido industrial no Brasil somente estaria concluída após o II PND, quando então começariam a surgir aqueles setores da economia que detêm urna íntima ligação com a indústria bélica, como será visto a seguir. Em relação ao segundo item, a obrigatoriedade de informar ao cedente qualquer aperfeiçoamento efetuado na tecnologia faz com que todos os compradores contribuam, gratuitamente, para que o vendedor e o dono da tecnologia centralizem o desenvolvimento da mesma. Beneficiando-se, simultaneamente, de todos os aperfeiçoamentos, o vendedor disporá sempre da melhor tecnologia, aquela que incorpora todos os avanços feitos. Desta forma, houve um grande desestímulo das empresas nacionais - sobretudo as empresas entrantes -, haja vista a transferência gratuita de tecnologia desenvolvida no setor doméstico para o exterior. Em realidade, esta segunda restrição funcionava como uma barreira à entrada das firmas, o que diminuía severamente o encadeamento da tecnologia bélica brasileira com a indústria civil.

A terceira cláusula restritiva seguramente é aquela que mais denota a restrição da disseminação do spin-off brasileiro. Isto ocorre em função da indústria, a montante, que se forma a reboque da indústria bélica. A produção de um simples item de um arsenal militar requer uma gama considerável de materiais e componentes, que são incorporados por outras firmas, que vão se formando ao mesmo tempo em que surge a própria indústria bélica.

Estas empresas que poderiam se formar por conta de um efeito multiplicador ficam limitadas por esta cláusula, cerceando desta forma a geração do spin-off, mesmo considerando a empresa estatal que surge na metade da década de setenta, a Imbel do Brasil S/A.

A justificativa para a importação da tecnologia é a necessidade de dispor de "engenharia medular", a qual está, normalmente, coberta por patentes ou sujeita a grande sigilo industrial. O fornecedor, como se pôde observar nas cláusulas de restrição, força a compra do pacote totalmente agregado, isto é, da "engenharia 
medular" somada à "engenharia periférica". ${ }^{6}$ Para forçar a compra casada, o vendedor alega que não pode oferecer garantias se o projeto não for comprado completo, ou que, para manter sigilo do processo, o projeto não poderá ser desmembrado para que parte seja entregue à engenharia local. Em geral, acaba-se exigindo a compra do detalhamento e, não raro, dos equipamentos (Longo, 1977).

Por fim, a compra de tecnologia sob a forma de pacote agregado reforça a dependência externa ao desencorajar as indústrias domésticas de bens de capital, ao mesmo tempo que aumenta o gasto de divisas com a importação de conhecimentos, serviços e componentes que poderiam ser produzidos no país.

\section{A forma como ocorre o desenvolvimento da tecnologia bélica}

A segunda condicionante parcial para que o processo de spin-off ocorresse foi a forma como se deu o desenvolvimento da tecnologia bélica - a aprendizagem.

Para desenvolver a tecnologia bélica pesada no Brasil, dois caminhos foram necessários: a capacitação técnica e a engenharia reversa, aos quais se soma, especialmente no caso dos blindados brasileiros, a repotencialização - considerada por muitos oficiais engenheiros como uma verdadeira escola. Esta última significou uma saída para as limitações impostas pela transferência de tecnologia e pela compra de pacotes tecnológicos.

Enquanto a capacitação técnica funciona como forma de adquirir os princípios da tecnologia, a repotencialização bem como a engenharia reversa funcionaram como formas de desenvolver a capacitação industrial bélica brasileira, viabilizando desta maneira a segunda condição para o spin-off. Em realidade, existiu uma dinâmica para a formação da base industrial bélica brasileira, que se confunde de certo modo com as condicionantes do spin-off. Esta dinâmica pode ser considerada como um ciclo de desenvolvimento que se inicia com a busca de tecnologia própria (como obter a tecnologia) através do uso intensivo de P\&D militar, e conclui com o envolvimento dos diversos setores da economia onde, então, se tem efetivamente a disseminação do spin-off. No entanto, a primeira fase desse processo exige combinar capacitação técnica/científica e capacitação industrial. No setor bélico, porém, esta última era bem limitada.

$\mathrm{Na}$ verdade, enquanto a indústria necessita de meios de produção, de mão-de obra qualificada e de novas técnicas, as instituições de pesquisa pura e aplicada produzem os meios humanos para serem agregados aos meios materiais necessários à produção da técnica e do conhecimento.

Desta forma, como explica Rodrigues: “ ... os militares brasileiros trabalharam procurando alcançar a capacitação técnica e científica junto com a capacitação

\footnotetext{
${ }^{6}$ Enquanto a engenharia medular designa as partes essenciais do projeto, tais como dimensionamento de equipamentos destinados à operação de processos unitários, a engenharia periférica compreende as partes consideradas acessórias, tais como projetos civis, elétricos e mecânicos, que são normalmente de inteiro domínio do país.
} 
industrial..." (Rodrigues, 1991, p. 218). No entanto, pese esta união ser condição sine qua non para a formação da indústria bélica, e consequentemente para a disseminação do spin-off, o segundo elemento da mesma era incipiente; logo, tentouse resolver o problema através da engenharia reversa e da repotencialização.

Com a implantação de novos institutos de pesquisa e a formação de pessoal qualificado - num processo começa do no início dos anos cinquenta — a formação de um complexo industrial bélico seria completada a partir da conquista da capacitação industrial, que foi conseguida em parte pelo aprendizado adquirido a partir da importação de produtos bélicos e, em parte, através da repotencialização dos produtos envelhecidos das Forças Armadas.

A engenharia reversa nada mais é do que procurar entender como foi desenvolvido determinado produto a partir de sua desmontagem completa e partir para sua cópia. Tal prática viabilizou o início de uma base industrial bélica para o Brasil, suprindo, com o passar do tempo, uma lacuna existente no ciclo de desenvolvimento da indústria bélica brasileira.

Por outro lado, a engenharia reversa é um processo que demanda tempo para que exista um refinamento na combinação da capacitação técnica e científica com a capacitação industrial, em função da complexidade do desenvolvimento da P\&D militar. Sendo ela um processo que permitirá a difusão de uma inovação através do aprendizado pela fabricação (learning by doing), é preciso lembrar que, conforme Deza:

“ ... a) o objetivo da difusão não é algo definitivo e invariável, mas algo que experimenta melhoras progressivas associadas ao processo de aprendizagem; b) o campo da difusão não está prefixado mas se desloca ao longo do tempo, como uma variável endógena do próprio processo de difusão; c) o comportamento dos agentes se caracteriza não pela imitação mas pela progressiva adaptação, não somente do usuário à nova técnica, senão desta à necessidade e limitações dos novos usuários. Nesse processo gradual a investigação técnica aparece como um agente fundamental na medida em que permite a transformação progressiva da inovação...” (Deza, 1995, p. 208)

O caminho percorrido nessa direção, pelo qual se buscou num primeiro momento o aprendizado pelo processo de engenharia reversa, foi fundamental para, num passo seguinte, partir para o aprendizado pelo uso do material importado dos EUA e Europa, desenvolvendo então a repotencialização dos carros blindados brasileiros - neste caso, o aprendizado pelo uso (learning by using). Ao se examinar um determinado item do arsenal militar, é preciso levar em conta a tecnologia central e as tecnologias paralelas envolvidas, ou seja, as tecnologias correlatas (Longo, 1977, p. 59).

Isto determina que uma maior incidência do spin-off ocorrerá em função da proximidade que exige da indústria civil doméstica, uma vez que o setor militar necessita do desenvolvimento de outros setores da economia não-bélica. No entan- 
to, este efeito somente seria sentido com maior intensidade a partir dos anos setenta, quando as expectativas colocadas na estratégia de buscar a engenharia reversa - para suprir a deficiência de capacitação industrial — estivessem maduras o suficiente para encadear vários setores da economia nacional. Isto foi conseguido a partir da engenharia reversa, como foi evidenciado pelo Grupo de Repotencialização de Blindados para o caso do Exército Brasileiro.

\section{A relação entre os dois setores envolvidos na dinâmica}

A relação da indústria civil com a indústria bélica serve como terceira condicionante do spin-off, na medida em que a maior proximidade de ambas permite a geração de conhecimento técnico/científico comum a determinadas necessidades; daí a conveniência de que exista uma proximidade estreita de alguns setores importantes da economia com a indústria bélica.

Basicamente duas formas são possíveis para verificar esta relação, observando se como estas promoveram o spin-off em alguns setores da economia nacional. A primeira forma está relacionada às empresas que não nasceram para a produção de material bélico mas, estimuladas pela demanda crescente deste setor no final dos anos sessenta, passaram também a produzir material bélico; a outra forma relaciona-se àquelas que nasceram em função da demanda militar doméstica e/ou internacional.

A formação do GPMI - Grupo de Mobilização Industrial — criado no final de 1963 - sem dúvida é um referencial que lançou bases para a conversão das empresas brasileiras em empresas produtoras de material bélico. Este grupo visava preparar as indústrias e as Forças Armadas para o período em que se supunha que intensos combates seriam travados entre forças do governo e a guerrilha antigolpe. Havia, desta forma, uma justificativa imediata para um esforço de produção local de material bélico (Rodrigues, 1991).

Este esforço inicialmente se concentrou na diversificação de um pequeno nicho produtivo existente que compreendia entre outros produtos: uniformes, munições, armas leves, viaturas leves, etc.

Entre esses novos produtos que começaram mais tarde a ser produzidos incluise o processo de repotencialização de armamentos existentes, transformando-os em mais avançados, tal como ocorreu com os sistemas de mira, blindagem, canhões, metralhadoras de calibre maior e embarcações, que mais tarde garantiram uma nova capacidade de produção em função da experiência adquirida. Foi a partir dessas experiências que várias empresas aderiram ao fabrico de material bélico.

Embora não tivessem nascido para a produção desses materiais, muitas delas converteram-se em função das experiências adquiridas com a realização de tarefas para as Forças Armadas. A Engesa, por exemplo, partiu da área de projetos e fabricação de peças e componentes para a prospecção de petróleo, passando depois para a produção de caminhões para terreno acidentado, onde, entre outros, a Petrobrás, a Cargill e a própria Marinha foram seus primeiros clientes. Com um grande conhecimento na tecnologia mecânica, devido à presença de oficiais enge- 
nheiros do Exército que trabalhavam no PqMM/2 (Parque de Manutenção e Motomecanização da Segunda Região Militar), não teve qualquer dificuldade em se direcionar para a nova demanda emergente. Somente mais tarde, com o sucesso do carro de combate Cascavel, principalmente no Oriente Médio, a Engesa entraria no segmento de eletrônica, com a compra da Bardella e uma unidade da empresa norte-americana Phillips. O caso da Bernardini é outro exemplo, pois além de fabricar cofres passou a produzir torres para carros de combate e suspensões. Com efeito, a Bernardini partiu de suas experiências na fabricação de fogões para a produção de cofres, e, no final dos anos sessenta, já repotencializava carros de combate advindos da Europa e EUA. A partir da experiência do manuseio do aço, metalurgia e mecânica, a Bernardini não teve grandes dificuldades para sua conversão bélica, devido à grande proximidade em que se encontrava com as necessidades das Forças Armadas brasileiras. A Avibrás, com sua experiência na produção de aeronaves civis, detinha um conhecimento de vanguarda nas áreas de mecânica de precisão, metalurgia e sistemas de propulsão; também não teve dificuldades em se orientar na produção de mísseis e peças de artilharia (Rodrigues, 1991, p. 201).

O caso da DF Vasconcellos Equipamentos Óticos, uma empresa tradicional de São Paulo fabricante de lupas, telescópios, teodolitos e binóculos, merece ser aqui destacado. Durante a etapa de desenvolvimento do míssil Piranha, desenvolvido pelo Instituto de Atividades Espaciais do Brasil, a DF foi contratada para desenvolver a cabeça inteligente do míssil, composta de sistemas óticos e de sensores do tipo infravermelho (Lopes, 1994, p. 123).

$\mathrm{Na}$ verdade, este foi um caminho natural para o desenvolvimento de projetos e a fabricação de material bélico no Brasil. No entanto, ao que tudo indica, o sucesso destas empresas na produção de armamentos deveu-se às experiências que elas traziam do setor civil.

Quando da conversão dessas e outras empresas para o setor bélico brasileiro, muitas delas continuaram a produzir produtos não-bélicos, o que de certa forma facilitou a disseminação do spin-off no Brasil. Um caso que pode servir de ilustração é o de Moto Peças, que, além de sua conversão para atender à demanda militar, continuava a produzir peças de reposição de automóveis, possibilitando, desta forma, transferir tecnologia desenvolvida na repotencialização de carros de combate para a indústria automobilística.

Esta experiência advinda da indústria civil possibilitou avanços importantes no setor bélico, mas também possibilitou um retorno à industria civil através do spin-off ou da tecnologia dual, uma vez que o domínio desta tecnologia tinha raízes na produção civil, facilitando seu emprego múltiplo.

Ao contrário das empresas, inteiramente privadas, que se converteram integral ou parcialmente para atender à demanda bélica, quase a totalidade das empresas que nasceram para atuar na produção de artefatos bélicos eram ou estatais ou sociedades de economia mista, a maior parte de cujo capital acionário era propriedade do Estado, sendo dirigidas por oficiais do Exército.

A indústria bélica brasileira, desde a sua formação até meados da década de 
sessenta, ficou ao cargo do Exército, através de suas fábricas e arsenais, o que definia uma solução estatal para a questão.

Os avanços conseguidos no final dos anos cinquenta marcaram de forma significativa a relação das empresas bélicas com a indústria civil através do emprego da tecnologia dual e o spin-off em alguns setores. No entanto, se por um lado as empresas que se converteram possibilitaram um importante e maior encadeamento por conta das experiências adquiridas na produção civil -, de outro as empresas que nasceram para a produção de material bélico, salvo algumas exceções, não possibilitaram um encadeamento tão expressivo.

Isto decorreu da própria especificidade destas empresas, que assumiram uma produção diferenciada daquelas que fizeram a conversão para a produção bélica. Enquanto as empresas convertidas, em sua maioria, procuraram desenvolver artefatos pesados, as empresas diretamente ligadas ao Estado especializaram-se, em grande parte, na produção de munições, armamento leve, equipamentos de radiocomunicação, material de campanha em geral etc. Essas empresas eram responsáveis em produzir grande parte dos artefatos bélicos empregados e consumidos pelo Exército. A absorção e algum aperfeiçoamento dessas tecnologias haviam ocorrido lentamente ao longo dos anos, propiciando alguma geração de conhecimento. No entanto, com a falta de uma política global, tudo ocorria de maneira assistemática, espontânea, sem a determinação segura de um planejamento, pois nenhuma das fábricas de controle estatal desenvolvia atividades organizadas de P\&D voltadas para a criação de uma tecnologia própria. Somente em 1970, com a criação do IPD, a indústria passou a contar com um processo mais planificado de P\&D.

\section{A mobilização industrial}

A mobilização industrial, como quarta condicionante, será considerada aqui como a ideia de um processo contínuo e planejado para um possível conflito, onde, a partir de um tecido industrial bélico formado, algumas empresas teriam condições de rapidamente abastecer de artefatos bélicos as Forças Armadas.

Previsto constitucionalmente, o processo de mobilização industrial bélico iniciou-se na primeira metade dos anos setenta, quando o governo Geisel rompeu o acordo de abastecimento de armas com os Estados Unidos, que desestimulava a produção nacional, e com o apoio do IPD e a criação da Imbel do Brasil S/A partiu para um processo de substituição de importações na indústria bélica brasileira.

Com seus objetivos claramente expressos, a Imbel do Brasil incorporou ao seu acervo as fábricas que pertenciam ao Exército: Andaraí, Realengo, Itajubá, Presidente Vargas e a fábrica Estrela de Juiz de Fora, entre outras.

Por outro lado ocorreu o surgimento de algumas empresas capazes de fabricar artigos de interesse militar, sendo que algumas conseguiram prosperar, mesmo que timidamente. De uma forma geral, as empresas que surgiram, não perdendo as características vislumbradas anteriormente, podem ser divididas em três grupos: as empresas pertencentes à Imbel; as empresas civis controladas por brasileiros, e as 
empresas civis controladas por capital estrangeiro. Além da natureza do capital destas empresas, a capacitação tecnológica servia como um diferenciador entre elas.

A Imbel enfrentou todas as dificuldades para a recuperação das fábricas incorporadas. Sob o ponto de vista tecnológico, ela recebeu um acervo desfalcado, já que as fábricas que foram transferidas já haviam perdido grande parte de seus recursos humanos e muitas estavam praticamente paralisadas há bastante tempo. Além disso, parte de seus planos de fabricação haviam sido entregues à indústria civil e parte de suas máquinas, arrendadas.

Com este processo, através do qual se pretendia mobilizar a indústria bélica nacional, é que tem-se a última condicionante para entender o spin-off no Brasil.

Via de regra, o órgão responsável que define as dotações de material bélico e o seu tipo é o Estado Maior das Forças Armadas. A partir do momento em que se opta pela nacionalização de um item de material bélico até a definição das características que o mesmo deve ter, o Estado Maior realiza um estudo do problema, gastando nisso cerca de um ano. Após este prazo é que o fabricante, já neste momento assessorado pelo departamento de pesquisa, recebe especificações e pode fazer uma estimativa de custo do projeto, fabricação de um protótipo e de uma posterior présérie (Catharino, 1980).

Outra questão que merece destaque é a capacitação técnico-científica militar, que no início dos anos setenta estava disponível apenas para os engenheiros que tiveram a oportunidade de desenvolver seus estudos em empresas nascentes no período ou participaram do processo de repotencialização.

Após a realização da estimativa de custo, o projeto deve entrar no planejamento financeiro da força armada, para que, cerca de dois anos mais tarde e com a concessão dos recursos, seja dada a ordem à indústria interessada, que inicia os trabalhos propostos. Percebe-se que se passaram, então, três anos desde o começo do processo.

Uma vez iniciado o projeto, aceita-se que para a realização do protótipo, seus testes, correções e modificações necessárias até que seja alcançado um nível razoável de qualidade no produto, deverão decorrer cerca de mais três anos, o que nos leva ao sexto ano. A partir daí inicia-se a fabricação da pré-série, sua entrega à tropa para adestramento e uso, a posterior coleta de dados relativos aos problemas decorrentes do uso do equipamento pela tropa e a correção destes problemas, até se chegar ao produto final, no que deverão decorrer cerca de mais dois anos.

A partir deste momento o produto está preparado para a produção em série, passando então o encargo de programação de sua compra ao departamento de material bélico da força armada. Supondo que o mesmo tenha recursos financeiros para a compra imediata do produto e faça sua encomenda à indústria, terá de se aparelhar em ferramental e pessoal, bem como escolher seus fornecedores, levando isto cerca de mais um ano. No entanto, em tempo de paz, o item normalmente é comprado pela força armada até o limite de sua dotação, dentro de um cronograma financeiro que, no mínimo, para um equipamento mais complexo, seria realizado num prazo nunca inferior a dois anos, o que na melhor das hipóteses acres- 
centaria pelo menos mais um ano até se atingir a dotação necessária. Chega-se a dez anos (Catharino, 1980).

Contudo, o processo não termina neste ponto, pois é muito improvável que uma única firma tenha capacidade para, em tempos de guerra, suprir a demanda de equipamentos exigidos pela operação de uma força armada. Neste momento é que surge a mobilização de outras indústrias similares, as que fornecerão ferramental, know how, assistência técnica e matéria-prima.

O processo de mobilização industrial descrito acima propicia, desta forma, a geração do spin-off sob dois aspectos: a manutenção da capacitação técnica militar na esfera produtiva de artefato bélico e/ou na esfera fornecedora de componentes e matéria-prima; e a aproximação maior e intensiva do setor bélico com o civil, que a mobilização exige para o sucesso da produção bélica de um país. Em se tratando da capacitação técnica, a mobilização industrial nos moldes apresentados anteriormente possibilita a maior incidência do spin-off, uma vez que mantém na órbita da indústria bélica o corpo de cientistas e técnicos. Na verdade, não existe outra maneira de assegurar no ambiente de desenvolvimento bélico tal capacitação, tendo em vista o plano de carreira dos oficiais das Forças Armadas. Segundo as normas da DMov (Diretoria de Movimentação do Exército) por exemplo, o oficial durante sua carreira pode ficar no máximo, em geral, quatro anos numa mesma organização militar, o que significa pouco aproveitamento - no caso do engenheiro militar - num processo de pesquisa e desenvolvimento bélico.

Percebe-se que antes do surgimento do IPD ou mesmo da Imbel, a permanência do corpo de oficiais nas empresas bélicas ou nos parques de motomecanização para desenvolver a repotencialização não seguia uma regra geral; o IPD foi pioneiro no sentido de apoiar politicamente, sem uma norma, a permanência de oficiais engenheiros nestas empresas.

Embora algum sucesso tenha sido alcançado neste período, o pouco dinamismo alcançado na mobilização não garantiu a permanência do corpo de engenheiros e cientistas na órbita da indústria bélica brasileira; isto comprova mais uma vez a pouca geração de spin-off na indústria civil no início da implantação de uma política de desenvolvimento bélico no país.

Com respeito à aproximação dos setores envolvidos, esta condicionante do spinoff revela que, no momento da mobilização industrial, há um encadeamento dos diversos setores da economia, que acabam funcionando como agentes promotores do desenvolvimento através da especialização em artefatos bélicos ou componentes e materiais correlatos e através da participação do corpo de engenheiros militares neste processo. $\mathrm{Na}$ verdade, esta maior aproximação viabiliza o salto qualitativo e quantitativo da tecnologia bélica para o ambiente civil.

No caso do processo de mobilização poderia se esperar um sucesso ainda maior, o que foi conseguido pelo menos até meados dos anos oitenta, quando então todo o setor entra em crise. 


\section{RESUMO E CONCLUSÃO}

O spin-off pode ser definido como um fenômeno de disseminação tecnológica que ocorre a partir do ambiente bélico gerando efeitos e encadeamentos em outros setores da economia nacional. No desenvolvimento dos processos de spin-off da indústria bélica brasileira quatro condicionantes devem ser consideradas: a origem da tecnologia bélica; a forma como ocorreu o desenvolvimento desta tecnologia; a relação das indústrias envolvidas no processo de disseminação; e a mobilização da indústria bélica brasileira.

A origem da tecnologia bélica funciona como condicionante para o spin-off na medida em que sua procedência está ligada à inovação de um determinado item ou produto bélico. No caso brasileiro isto pôde ocorrer de duas formas: com a inovação desenvolvida internamente e com a busca de tecnologia fora do país.

A tecnologia desenvolvida internamente é responsável por uma disseminação mais rápida do spin-off, devido a sua aplicação ser possível tanto no ambiente bélico como no civil. No caso da tecnologia que acompanha os pacotes ou nos raríssimos casos de transferência, a disseminação ocorre de forma mais lenta e é possível, inclusive, que não ocorra devido às restrições que as acompanham.

A forma como ocorreu o desenvolvimento da tecnologia bélica - a aprendizagem - revela outra característica do spin-off no Brasil. Por conta da inexistência de uma prévia capacitação industrial bélica, a tecnologia desenvolvida internamente começou a partir da engenharia reversa (learning by doing) e da repotencialização (learning by using) para adquirir capacitação industrial e posteriormente inovar. Se este processo foi de tentativas e erros (bem como apresentou certa lentidão), o mesmo projetou o país no início dos anos oitenta como um dos principais produtores de armamento do mundo.

A relação das indústrias bélica e civil funcionou como uma das condicionantes para o spin-off por conta da relação natural existente entre alguns desses setores, que normalmente estão incluídos entre aqueles que detêm um certo grau de tecnologia e, devido à sua proximidade, acabam por encadear efeitos positivos na economia. O processo de mobilização industrial bélico promovido a partir da segunda metade da década de setenta funcionou como uma condição para o spin-off brasileiro, uma vez que tal processo aproxima as indústrias bélica e civil a partir de uma política de desenvolvimento industrial articulada com os interesses gerais do país, o que possibilitou um avanço razoável de desenvolvimento industrial, consolidando o spin-off sobretudo na área automobilística.

Todavia, enquanto as três condicionantes iniciais para o spin-off no Brasil ocorreram espontaneamente, a quarta condicionante depende de alguns fatores que devem ser levados em conta para reflexão.

O primeiro deles refere-se ao II PND - Plano Nacional de Desenvolvimento -, que tinha como referencial o Brasil "potência". A necessidade de o Brasil ampliar seu parque industrial bélico - mesmo a um custo elevado de endividamento externo - para estar minimamente preparado diante de um conflito internacional 
no contexto da Guerra Fria impulsionou esta condicionante, possibilitando os encadeamentos tecnológicos da indústria bélica para a indústria civil.

Por outro lado, nota-se que com as crises internacionais que ocorreram desde o final da segunda metade da década de setenta houve uma desarticulação do processo de mobilização industrial. Assim, a partir dos anos oitenta, o Estado não conseguiu orientar uma política de desenvolvimento industrial através do sistema de cooperação bélico-civil, o que fragilizou o tecido industrial bélico, com a falta de fundos para a P\&D que não podem ser pensados separadamente do desenvolvimento industrial e que, além disso, representam a pedra angular para o spin-off.

Outro fator não menos importante refere-se às prioridades tomadas pelo governo brasileiro no mesmo período, com o III PND. Embora os planos nacionais de desenvolvimento da década de setenta tivessem como proposta um processo contínuo, o III PND, do governo Figueiredo, teve que ser abandonado, priorizando o ajuste externo, deixando para trás qualquer tentativa de levar adiante o processo de mobilização industrial. É importante notar que tal processo, se levado a cabo, representaria um esforço de cooperação industrial entre a indústria bélica brasileira e a indústria civil que, com o conhecimento gerado a partir das três outras condicionantes, poderia manter e provavelmente ampliar a incidência do spin-off no Brasil, tais como foram, e são, os casos dos Estados Unidos, França, Bélgica e outros.

Desta forma, o processo de manutenção do spin-off no Brasil bem como sua possibilidade de ampliação fragilizou-se em virtude de uma política que, se por um lado serviu como base para iniciar um esforço de cooperação industrial, por outro não conseguiu se manter em virtude das dificuldades internacionais e das prioridades estabelecidas pelo governo brasileiro, mesmo tendo presentes as três condicionantes anteriores, as quais, embora sejam parte integrante do spin-off brasileiro, não são suficientes sem o esforço de cooperação conhecido por mobilização industrial.

Assim, a possibilidade de que o spin-off volte a ocorrer - embora ao que tudo indica venha ocorrendo timidamente por ser espontâneo - depende diretamente do resgate de uma política de desenvolvimento industrial que tenha como base a cooperação industrial que permite a aproximação entre a indústria bélica e a indústria civil e a interligação da $P \& D$ das indústrias envolvidas na dinâmica

\section{REFERÊNCIAS BIBLIOGRÁFICAS}

ASSAOKA, Alberto (1983) Aços de Alta Resistência Temperados e Revenidos, manuscrito não publicado.

CATHARINO FINATO, Walter (1980) Descrição Sumária dos Proietos Militares Bernardini e os Problemas Envolvidos para sua Realização, manuscrito não publicado.

CONCA, Ken (1990) O Brasil na Economia Global de Armamentos, Tese de Doutorado.

DAGNINO, Renato Peixoto (1993) Uma Avaliação da Indústria Bélica Brasileira: Defesa, Indústria e Tecnologia, Grupo de Estudos Estratégicos; Rio de Janeiro.

DEZA, Xavier Vence (1995) Economía de la Innovación y Cambio tecnológico: Una revisión crítica, Madrid, Siglo XXI de España Editores S.A. 
FONSECA, José Wladimir Freitas da (1997) A Transferência de Tecnologia da Indústria Bélica Brasileira para a Indústria Civil: o caso da indústria automobilística, Dissertação de Mestrado.

LONGO, Waldimir Pirró e (1977) Tecnologia e Transferência de Tecnologia - Problemas Atuais da Indústria Bélica Nacional, Monografia da Escola de Comando e Estado Maior do Exército.

LOPES, Roberto (1994) Rede de Intrigas: os bastidores do fracasso da indústria bélica no Brasil, Record; Rio de Janeiro.

MENDES, Silverio (1979) Transferência de Tecnologia — Um Problema Atual da Indústria Bélica Nacional, Monografia da Escola de Comando e Estado Maior do Exército.

PROENÇA JUNIOR, Domício (1987) Perfil Histórico-Bibliográfico da Indústria Bélica Brasileira, Dissertação de Mestrado.

RESEARCH, Development and Acquisition - Military-Civilian Technology Transfer; Headquarters Department of the Army; Washington, D.C. 25 July 91.

RODRIGUES, José de Souza (1991) A Indústria de Material Bélico Brasileiro como Formadora da Base Tecnológica, Industrial e Científica do Brasil, Dissertação de Mestrado. 